\title{
ANALISIS KORELASI ANTARA MATERI GEOMETRIBANGUN DATAR PADA PEMBELAJARAN MATEMATIKA DI SEKOLAH DENGAN MATERI OSN MATEMATIKA TINGKAT SEKOLAH MENENGAH PERTAMA
}

\author{
Sri Hartatik ${ }^{1)}$, Teguh Herlambang ${ }^{2)}$ \\ ${ }^{1)}$ PGSD, FKIP, Universitas Nahdlatul Ulama Surabaya \\ ${ }^{2)}$ Sistem Informasi, FT., Universitas Nahdlatul Ulama Surabaya \\ Email: titax@unusa.ac.id
}

\begin{abstract}
Abstrak. Penelitian ini bertujuan untuk mendeskripsikan tentang korelasi antara materi Geometri Bangun Datar di sekolah dengan materi OSN bidang Matematika di Tingkat Sekolah Menengah Pertama.

Jenis penelitian ini adalah penelitian kualitatif. Data yang digunakan dalam penelitian ini yaitu data primer data sekunder. Data primer yang dimaksud adalah hasil tes pemecahan masalah OSN matematika siswa SMPN 32 Surabaya dan Data sekunder yang dimaksud dalam ppenelitian ini adalah Bank Soal OSN Bidang Matematika tingkat kabupaten/kota tahun 2015. Tujuan dari penelitian ini untuk menganalisis kesesuaian materi geometri pada soal-soal olimpiade dengan SK dan KD matematika pada kurikulum 2013.

Berdasarkan analisis data, untuk bank soal OSN matematika, terdapat 6 soal dari 25 soal yang ada merupakan soal geometri bangun datar. Dari hasil analisa ke enam soal OSN Matematika materi Geometri bangun datar didapatkan bahwa dari 6 soal yang ada , 5 soal tidak sesuai dengan KD yang ada sedangkan 1 soal sesuai dengan KD pada kurikulum 2013. Berdasarkan jenis soal 5 soal termasuk ke dalam soal non rutin sedangkan 1 soal termasuk ke dalam soal rutin. Berdasarkan keterkaitan soal, hampir keseluruhan soal terkait dengan beberapa konsep sehingga siswa diharapkan mampu mengkaitkan antara konsep yang ada sehingga akan diperoleh solusi yang diharapkan.
\end{abstract}

Kata kunci : Geometri bangun datar, OSN bidang Matematika

Abstract. His study aimed to describe the correlation between matter Geometry Build Flat in school with OSN material Mathematics at Junior Secondary Level. This research is a qualitative research. The data used in this research is primary data secondary data. Primary data is the result of OSN problem solving tests mathematics students of SMPN 32 Surabaya and secondary data referred to in this ppenelitian is OSN Mathematics Test Bank district / city level in 2015. The aim of this study to analyze the suitability of the material geometry on matters Olympics SK and KD mathematics curriculum in 2013.

Based on data analysis, for OSN math question bank, there are 6 questions of 25 questions that there is a matter of waking up flat geometry. From the analysis to the six questions OSN Mathematics Geometry Flat material was found that from about the existing 6, 5 question does not comply with the existing KD while the first question in accordance with KD in 2013. Based on the type of curriculum about five questions included in nonroutine matter while 1 question belong to a routine matter. Based on the linkage problem, almost the entire matter related to some of the concepts that students are expected to link the concept that there is thus obtained the expected solution.

Keywords : two-dimentional figuregeometry, OSN Math 


\section{PENDAHULUAN}

Olimpiade Sains Nasional (OSN ) adalah ajang berkompetisi dalam bidang sains bagi para siswa pada jenjang SD, SMP, dan SMA di Indonesia. Olimpiade Sains Nasional diadakan sekali dalam satu tahun di kota yang berbeda-beda.

OSN pertama dilaksanakan di PPPPTK Matematika (waktu itu masih bernama PPPG Matematika ) Yogyakarta pada September 2002. Pada tahun tersebut masih melombakan pada tingkat jenjang SMA.Soal-soal OSN dirancang agar menjadi masalah bagi setiap pesertanya, sehingga para peserta OSN ditantang untuk belajar berpikir, bernalar, dan memecahkan masalah.

NRC (1989) menyatakan bahwa “ Mathematics is a science of patterns and order" artinya, matematika itu merupakan ilmu yang membahas tentang pola atau keteraturan dan tingkatan. Sedangkan De Lange (2004: 8) Menyatakan bahwa matematika dapat dilihat sebagai bahasa yang menjelaskan tentang pola baik pola di alam dan amaupun pola yang ditemukan melalui pikiran. Pola-pola tersebut bisa berbentuk real (nyata) maupun berbentuk imajinasi, dapat dilihat atau dapat dalam bentuk mental, statis atau dinamis, kualitatif atau kuantitatif, asli berkaitan dengan kehidupan nyata sehari-hari atau tidak lebih dari sekedar, dari, kedalaman ruang dan waktu, atau dari hasil pekerjaan pikiran insani.

Dreescu \& Gelga (2009 : 15) yang artinya bahwa masalah jelas berbeda dengan soal Latihan. " soal latihan " didefinisikan sebagai ketika anda melihatnya maka anda dapat dengan cepat menyelesaikannya. Menurut Aisyah Nyimas (2008) : Masalah bersifat relatif, artinya masalah bagi seseorang pada suatu saat belum tentu merupakan masalah bagi orang lain pada saat itu atau bahkan bagi orang itu sendiri beberapa saat kemudian.Maksudnya adalah masalah untuk siswa kelas 1 SD belum tentu menjadi masalah bagi siswa SMP. Atau masalah untuk siswa SMP kelas VII belum tentu merupakan masalah untuk siswa kelas VIII, sehingga masalah bisa jadi tidak menjadi masalah bagi orang lain jika orang tersebut mampu menyelesaikan persoalan tersebut.

Soal- soal matematika dibedakan menjadi dua macam yaitu soal rutin dan soal non rutin. Soal rutin adalah soal latihan biasa yang dapat diselesaikan dengan prosedur yang dapat dipelajari di kelas. Soal jenis ini banyak terdapat dalam buku-buku ajar siswa dan dimaksudkan untuk melatih siswa dalam menggunakan prosedur pemecahan masalah yang sudah diajarkan di kelas. Sedangkan untuk soal non rutin adalah soal yang untuk menyelesaikannya diperlukan pemikiran yang lebih lanjut karena prosedur 
penyelesaiannya belum jelas atau tidak sama dengan prosedur yang dipelajari di kelas. Ada beberapa karakteristik masalah matematika (soal non rutin ) antara lain :

a. Memiliki lebih dari satu cara penyelesaian

b. Memiliki lebih dari satu jawaban

c. Melibatkan logika, penalaran, dan uji coba

d. Sesuai dengan situasi nyata dan minat siswa.

Dalam penelitian ini soal matematika dikatakan soal non rutin jika minimal memiliki 1 karakteristik diatas.

Salah satu dari lima tujuan pembelajaran matematika menurut standar Isi MataPelajaranMatematika (Depdiknas, 2006) yang harus tetap diacu para guru selama proses pembelajaran di kelas, adalah "menggunakan penalaran pada pola dan sifat, melakukan manipulasi matematika dalam membuat generalisasi, menyusun bukti, atau menjelaskan gagasan dan pernyataan matematika".

Menurut IG.A.K Wardani (2014: 2.8) kemampuan memecahkan masalah (problem solving), yang mencakup merasakan adanya masalah, kemampuan berkomunikasi, mengidentifikasi masalah, mencari informasi untuk memecahkan masalah, mengeksplorasi alternatif pemecahan masalah, dan memilih alternatif yang paling layak.Kemampuan siswa SMP dalam memecahkan masalah OSN Matematika sangat rendah. Hal ini dapat dibuktikan dengan adanya kemampuan siswa dalam menyelesaikan soal prediksi OSN Matematika sangat rendah. Dari 30 soal yang diberikan, rata-rata siswa hanya mampu menyelesaikan soal sebanyak 4 soal dengan tingkat kebenaran sebesar 25\%. Dari hasil pretes yang ada siswa banyak yang belum mampu menyelesaikan dengan baik soal yang ada. Berdasarkan kemampuan siswa dalam menyelesaikan masalah OSN bidang matematika maka peneliti ingin mengetahui kesesuaian materi pembelajaran matematika yang mereka peroleh di sekolah dengan materi OSN matematika pada tingkat Sekolah Menengah pertama berdasarkan.

Geometri merupakan salah satu cabang matematika yang mempelajari masalah bentuk, ukuran, posisi relatif gambar, dan sifat ruang. Geometri bangun datar merupakan salah satu inti dari pembelajaran geometri dimensi dua. Di dalam materi geometri bangun datar datar ini, kamu akan mengenal dan mempelajari mengenai beberapa jenis bangun datar (bangun dimensi dua), mulai dari sifat-sifatnya hingga penghitungan luas dan kelilingnya serta penggunaanya dalam memecahkan masalah. Berikut ini beberapa SK dan KD Kurikulum 2013 yang berhubungan dengan geometri datar. 
Tabel 1. SK dan KD Materi Geometri berdasarkan Kurikulum 2013

\begin{tabular}{|c|c|c|}
\hline Kelas & tandart Kompetensi & nsi Dasar \\
\hline VII & $\begin{array}{l}\text { 2. Menghargai dan menghayati } \\
\text { perilaku jujur, disiplin, } \\
\text { tanggungjawab, peduli (toleransi, } \\
\text { gotong royong), santun, percaya diri, } \\
\text { dalam berinteraksi secara efektif } \\
\text { dengan lingkungan sosial dan alam } \\
\text { dalam jangkauan pergaulan dan } \\
\text { keberadaannya } \\
\text { 3. Memahami pengetahuan (faktual, } \\
\text { konseptual, dan prosedural) } \\
\text { berdasarkan rasa ingin tahunya } \\
\text { tentang ilmu pengetahuan, teknologi, } \\
\text { seni, budaya terkait fenomena dan } \\
\text { kejadian tampak mata } \\
\text { 4. Mencoba, mengolah, dan menyaji } \\
\text { dalam ranah konkret (menggunakan, } \\
\text { mengurai, merangkai, memodifikasi, } \\
\text { dan membuat) dan ranah abstrak } \\
\text { (menulis, membaca, menghitung, } \\
\text { menggambar, dan mengarang) sesuai } \\
\text { dengan yang dipelajari di sekolah dan } \\
\text { sumber lain yang sama dalam sudut } \\
\text { pandang/teori }\end{array}$ & $\begin{array}{l}\text { 2.4 Menunjukkan perilaku disiplin dalam } \\
\text { melakukan aktivitas di rumah, sekolah, } \\
\text { dan masyarakat sebagai wujud } \\
\text { implementasi pelaksanakan prosedur } \\
\text { dalam menggambar segitiga, garis } \\
\text { tinggi, garis bagi, garis berat, dan garis } \\
\text { sumbunya menggunakan penggaris, } \\
\text { jangka, dan busur } \\
\text { 3.6 Memahami sifat-sifat bangun datar dan } \\
\text { menggunakannya untuk menentukan } \\
\text { keliling dan luas } \\
\text { 3.7 Mendeskripsikan lokasi benda dalam } \\
\text { koordinat Kartesius } \\
\text { 3.8 Menaksir dan menghitung luas } \\
\text { permukaan bangun datar yang tidak } \\
\text { beraturan dengan menerapkan prinsip- } \\
\text { prinsip geometri } \\
\text { 4.7 Menyelesaikan permasalahan nyata } \\
\text { yang terkait penerapan sifat-sifat } \\
\text { persegi panjang, persegi, trapesium, } \\
\text { jajargenjang, belah ketupat, dan layang- } \\
\text { layang }\end{array}$ \\
\hline VI & $\begin{array}{l}\text { ahami dan menerapkan } \\
\text { huan (faktual, konseptual, dan } \\
\text { Iral) berdasarkan rasa ingin } \\
\text { tentang ilmu pengetahuan, } \\
\text { gi, seni, budaya terkait } \\
\text { na dan kejadian tampak mata }\end{array}$ & $\begin{array}{l}\text { 3.6 Memahami unsur, keliling, dan luas } \\
\text { dari lingkaran } \\
\text { 3.7 Memahami hubungan sudut pusat, } \\
\text { panjang busur, dan luas juring } \\
\text { 3.8 Memahami Teorema Pythagoras } \\
\text { melalui alat peraga dan penyelidikan } \\
\text { berbagai pola bilangan }\end{array}$ \\
\hline IX & $\begin{array}{l}\text { 2. Menghargai dan menghayati perilaku } \\
\text { jujur, disiplin, tanggungjawab, peduli } \\
\text { (toleransi, gotong royong), santun, } \\
\text { percaya diri, dalam berinteraksi } \\
\text { secara efektif dengan lingkungan } \\
\text { sosial dan alam dalam jangkauan } \\
\text { pergaulan dan keberadaannya } \\
\text { 3. Memahami dan menerapkan } \\
\text { pengetahuan (faktual, konseptual, } \\
\text { dan prosedural) berdasarkan rasa } \\
\text { ingin tahunya tentang ilmu } \\
\text { pengetahuan, teknologi, seni, budaya } \\
\text { terkait fenomena dan kejadian } \\
\text { tampak mata }\end{array}$ & $\begin{array}{l}\text { 2.1 Menunjukkan perilaku ingin tahu } \\
\text { dalam melakukan aktivitas di rumah, } \\
\text { sekolah, dan masyarakat sebagai wujud } \\
\text { implementasi mempelajari sifat-sifat } \\
\text { segitiga sebangun dan kongruen. } \\
\text { 3.6 Memahami konsep kesebangunan dan } \\
\text { kekongruenan geometri melalui } \\
\text { pengamatan } \\
\text { 3.8 menaksir dan mengitung luas } \\
\text { permukaan bangun datar dan bangun ruang } \\
\text { yang tidak beraturan denganmenerapkan } \\
\text { kombinasi geometri dasarnya }\end{array}$ \\
\hline
\end{tabular}

Metode penelitian ini menggunakan metode penelitian kualitatif. Data yang digunakan dalam penelitian ini ada 2 yaitu data primer berupa hasil pemecahan masalah
OSN, dimana data tersebut dapat digunakan sebagai data awal dalam penelitian ini. Sedangkan data ke sekunder dalam penelitian ini adalah berkas soal OSN 
Matematika tingkat kabupaten/ kota yang diselenggarakan pada tanggal 9 Maret 2015. Dalam penelitian ini peneliti menganalisa soal-soal geometri bangun datar yang terdapat pada soal seleksi OSN matematika. BerkasSoal terdiri dari 15 soal pilihan ganda dan 10 soal uraian singkat. Dari 25 soal yang diberikan, ada 6 soal dengan konten materi Geometri Bangun Datar. 5 soal pada pilihan ganda dan 1 soal pada uraian. Dari keenam soal tersebut dianalisis berdasarkan jenis soal apakah termasuk pada soal rutin atau soal non rutin. Dan kesesuaian materi yang ada dengan materi geometri bangun datar pada kurikulum 2013.

\section{HASIL DAN PEMBAHASAN}

Hasil analisis soal OSN berdasarkan SK dan KD Kurikulum 2013 adalah sebagai Berikut :

\section{Analisis soal nomor 4}

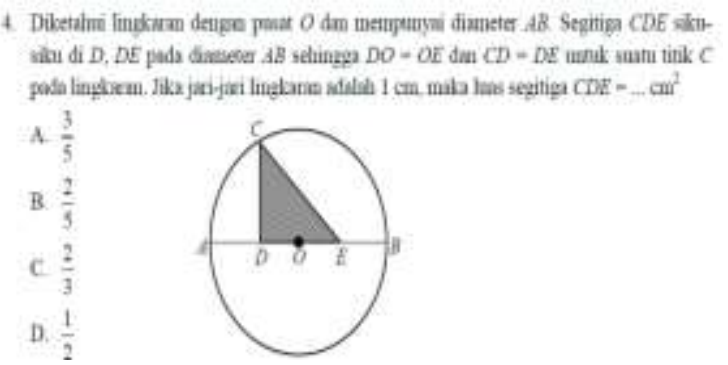

Untuk soal nomor 4 merupakan soal geometri. Siswa dituntut untuk dapat menghitung luas segitiga siku siku CDE yang berada di dalam lingkaran yang berdiameter $\mathrm{AB}$ dan berpusat $\mathrm{O}$ dengan panjang jari-jari $1 \mathrm{~cm}$. DE pada diamter $\mathrm{AB}$ sehingga $\mathrm{DO}=\mathrm{OE}$ dan $\mathrm{CD}=\mathrm{DE}$. Untuk dapat menghitung luas segitiga CDE, siswa harus mengetahui terlebih dahulu berapa panjang DO. Soal tidak sesuai dengan KD kelas VII 3.6 "Memahami unsur, keliling, dan luas dari lingkaran" karena sesuai dengan KD tersebut siswa hanya mampu menjelaskan, memperkirakan, mencirikan, membandingkan, menghitung, menguraikan dan menyimpulkan tetapi siswa belum mampu untuk menerapkan konsep untuk menyelesaikan masalah. Soal tersebut merupakan soal non rutin karena soal tersebut merupakan jenis soal yang membutuhkan penalaran danpemahaman yang lebih sehingga siswa mampu mengkaitkan antara apa yang diketahui dengan yang akan dicari.

Analisis soal nomor 5

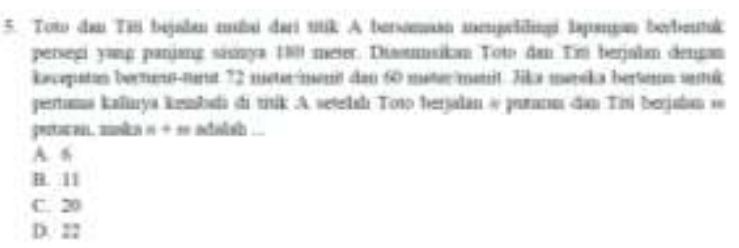

soal no 5, merupakan kombinasi antara soal geometri yaitu keliling persegi sebagai bentuk lapangan dan teori bilangan dalam hal ini adalah kelipatan yaitu pada kalimat kunci " mereka bertemu pertama kalinya dititik A". Siswa dituntut untuk dapat menjumlah putaran Toto dan Putaran Titi. Soal diatas sesuai dengan KD kelas VII 3.6 "Memahami sifat-sifat bangun datar dan menggunakannya untuk menentukan keliling dan luas akan tetapi kurang sesuai dengan KD 3.1yaitu "Membandingkan dan mengurutkan berbagai jenis bilangan serta menerapkan operasi hitung bilangan bulat dan bilangan pecahan dengan memanfaatkan berbagai sifat operasi" pada kelas VII karena pada soal siswa tidak diharuskan mengurutkan tetapi siswa bisa menggunakan konsep kelipatan persekutuan terkecil. Soal tersebut merupakan soal non rutin karena untuk menyelesaikan masalah tersebut membutuhkan penalaran yang lebih tinggi. Dan memiliki lebih dari satu cara penyelesaian.

Analisis soal nomor 11

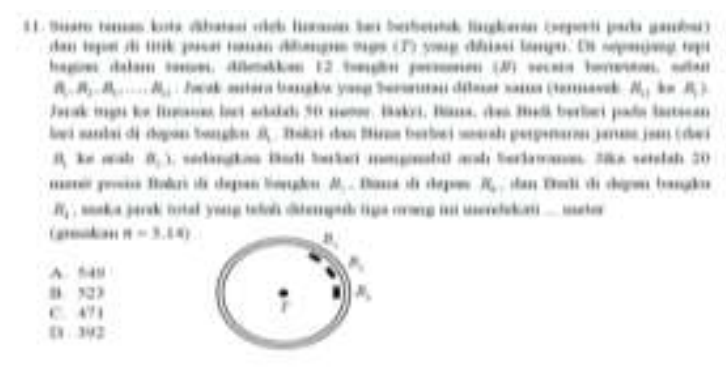


Untuk soal nomor 11, merupakan soal non rutin geomteri dengan tipe soal cerita dengan tingkat kesukaran yang tinggi, karena untuk menyelesaikan soal tersebut membutuhkan kemampuan pemecahan masalah yang tinggi. Siswa harus mampu mengidentifikasi masalah yang terdapat pada soal tersebut, kemudian siswa diharapkan mampu mengaitkan informasi yang sudah mereka peroleh untuk mendapatkan solusi dari masalah. Materi soal adalah geometri yang berhubungan dengan keliling lingkaran. Soal tersebut tidak sesuai dengan KD kelas VIII 3.6 "Memahami unsur, keliling, dan luas dari lingkaran." Karena pada KD tersebut siswa diharapkan hanya memahami unsur keliling saja dan tidak menggunakan unsur tersebut dalam menyelesaikan masalah sehari-hari yang berhubungan dengan keliling.

Analisis soal nomor 12

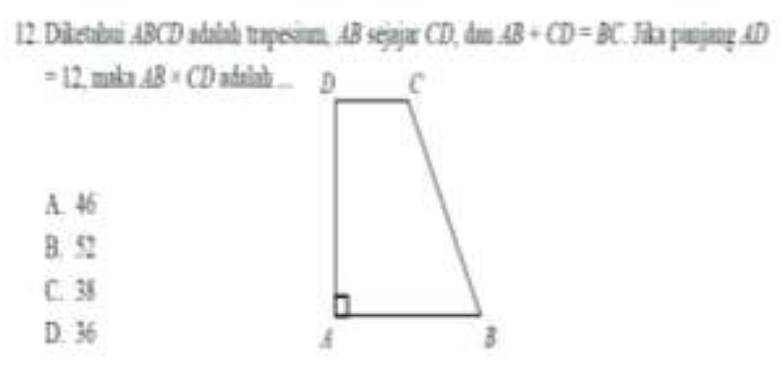

Untuk soal no 12, merupakan rutin dengan materi geometri. Untuk dapat menyelesaikan masalah nomor 12 , siswa diharapkan mempunyai kemampuan pemecahan masalah yang tinggi dan membutuhkan penalaran yang tinggi juga. Siswa harus mampu mengkaitkan antara apa yang diketahui seperti bentuk bangun datar trapesium, mempunyai 2 sisi yang sejajar, panjang $\mathrm{AD}=12 \mathrm{~cm}$ dan $\mathrm{AB}+\mathrm{CD}=\mathrm{BC}$ dengan pengetahuan yang dimiliki sehingga mampu menyelesaikan masalah. Konten materi soal sesuai dengan KD kelas VII 4.7 "Menyelesaikan permasalahan nyata yang terkait penerapan sifat-sifat persegi panjang, persegi, trapesium, jajargenjang, belah ketupat, dan layang-layang."
Analisis soal no 15

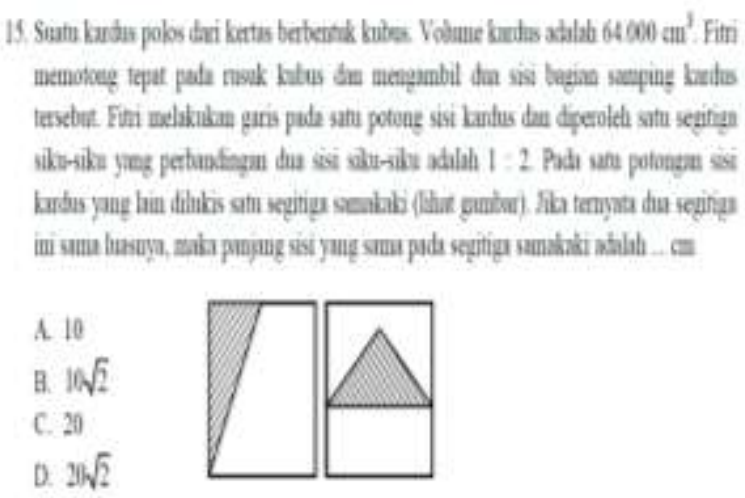

Untuk soal nomor 15 merupakan soal geometri yang merupakan kombinasi dari bangun ruang, bangun datar, dan konsep perbandingan.Soal nomor 15 merupakan soal non rutin karena memiliki lebih dari satu cara penyelesaian, membutuhkan penalaran dan logika yang lebih untuk dapat menyelesaikan masalah tersebut. Konten materi pada soal tersebut tidak sesuai dengan KD kelas VII3.6 "Memahami sifat-sifat bangun datar dan menggunakannya untuk menentukan keliling dan luas " Karena untuk memecahkan masalah pada nomor 15 diperlukan kemampuan kognitif dengan tahapan analisis dimana siswa harus mampu mengkorelasikan antara konsep perbandingan dengan konsep bangun datar yang lain seperti gambar yang terdapat pada soal nomor 15 .

\section{Tipe soal Uraian}

\section{Analisis soal nomor 3}

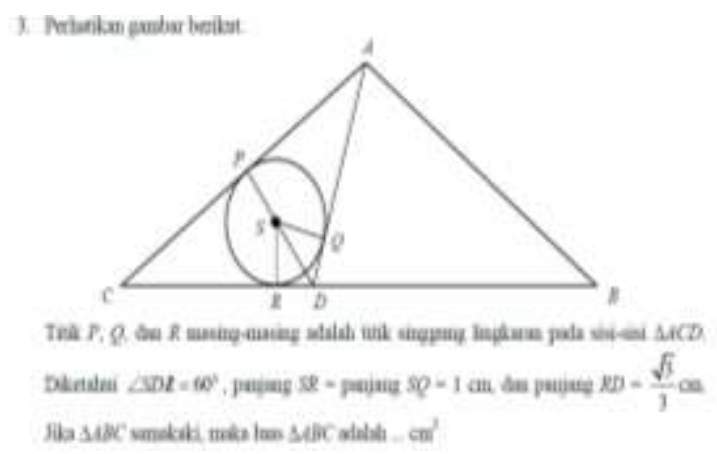

Untuk soal nomor 3, merupakan soal geometri bangun datar.Soal tersebut merupakan soal non rutin/ masalah matematika karena soal tersebut membutuhkan penalaran dan pemahaman 
yang tinggi tentang geomteri bangun datar. Disamping itu pula soal tersebut juga memiliki lebih dari satu penyelesaian. Konten materi soal tersebut tidak sesuai dengan KD kelasVII Nomor3.6 "Memahami sifat-sifat bangun datar dan menggunakannya untuk menentukan keliling dan luas. " karena pada KD siswa hanya mampu memahami dan menentukan keliling dan luas akan tetapi pada soal nomor 3 siswa belum diharapkan mampu menyelesaikan dengan cara mengkaitkan antara titik singgung lingkaran, panjang garis SR, SQ, RD dan sudut SDR dengan segitiga $A B C$ yang sama kaki sehingga diperoleh luas segitiga ABC.

Dari hasil analisa diatas dapat disimpulkan bahwa :

\begin{tabular}{|c|c|c|c|c|}
\hline $\begin{array}{l}\text { Soal } \\
\text { Nomor }\end{array}$ & Jenis Soal & $\begin{array}{l}\text { Soal Non } \\
\text { Rutin / } \\
\text { soal rutin }\end{array}$ & $\begin{array}{ll}\text { Kesesuaian } & \text { Materi } \\
\text { berdasarkan SK dan KD } \\
\text { Kurikulum 2013 }\end{array}$ & $\begin{array}{l}\text { Keterkaitan antara } \\
\text { konsep }\end{array}$ \\
\hline 4 & Pilihan ganda & $\begin{array}{l}\text { Soal Non } \\
\text { Rutin }\end{array}$ & $\begin{array}{l}\text { Tidak sesuai dengan } \mathrm{KD} \\
\text { kelas VII } 3.6\end{array}$ & $\begin{array}{lr}\text { Mengkaitkan } & \text { antara } \\
\text { konsep } & \text { lingkaran } \\
\text { dengan } & \text { konsep } \\
\text { segitiga siku-siku }\end{array}$ \\
\hline 5 & Pilihan ganda & $\begin{array}{l}\text { Soal Non } \\
\text { rutin }\end{array}$ & $\begin{array}{l}\text { sesuai dengan KD kelas } \\
\text { VII } 3.6\end{array}$ & $\begin{array}{lr}\text { keliling } & \text { persegi } \\
\text { sebagai } & \text { bentuk } \\
\text { lapangan dan } & \text { teori } \\
\text { bilangan } & \\
\end{array}$ \\
\hline 11 & Pilihan ganda & $\begin{array}{l}\text { Soal Non } \\
\text { rutin }\end{array}$ & $\begin{array}{l}\text { tidak sesuai dengan } \mathrm{KD} \\
\text { kelas VIII } 3.6\end{array}$ & $\begin{array}{lr}\text { Konsep } & \text { keliling } \\
\text { lingkaran dan jarak } \\
\text { tempuh }\end{array}$ \\
\hline 12 & Pilihan ganda & Soal rutin & $\begin{array}{l}\text { sesuai dengan KD kelas } \\
\text { VII } 4.7\end{array}$ & $\begin{array}{ll}\text { Unsur } & - \text { unsur } \\
\text { trapesium } & \\
\end{array}$ \\
\hline 15 & Pilihan ganda & $\begin{array}{l}\text { Soal non } \\
\text { rutin }\end{array}$ & $\begin{array}{lrl}\text { tidak sesuai } & \text { dengan } & \mathrm{KD} \\
\text { kelas VII } 3.6 & & \end{array}$ & $\begin{array}{l}\text { Mengkaitkan antara } \\
\text { konsep volume } \\
\text { kubus, bangun datar } \\
\text { (segi tiga dan } \\
\text { Persegi) dengan } \\
\text { konsep perbandingan }\end{array}$ \\
\hline 3 & $\begin{array}{l}\text { Uraian } \\
\text { singkat }\end{array}$ & $\begin{array}{l}\text { Soal Non } \\
\text { rutin }\end{array}$ & $\begin{array}{l}\text { tidak sesuai dengan } \mathrm{KD} \\
\text { kelas VII Nomor } 3.6\end{array}$ & $\begin{array}{l}\text { Untuk memperoleh } \\
\text { luas segitiga, perlu } \\
\text { mengkaitkan konsep } \\
\text { segitiga ACD } \\
\text { dengan titik } \\
\text { singgung lingkaran }\end{array}$ \\
\hline
\end{tabular}

\section{Kesimpulan}

Dari hasil analisa ke enam soal OSN Matematika materi Geometri bangun datar didapatkan bahwa dari 6 soal yang ada , 5 soal tidak sesuai dengan $\mathrm{KD}$ yang ada sedangkan 1 soal sesuai dengan KD pada kurikulum 2013. Berdasarkan jenis soal 5 soal termasuk ke dalam soal non rutin sedangkan 1 soal termasuk ke dalam soal rutin. Berdasarkan keterkaitan soal, hampir keseluruhan soal terkait dengan beberapa konsep sehingga siswa diharapkan mampu mengkaitkan antara konsep yang ada sehingga akan diperoleh solusi yang diharapkan.

\section{DAFTAR PUSTAKA}

Aisyah, Nyimas. (2008). Pengembangan Pembelajaran matematika SD. Jakarta: Dirjen Dikti.

Depdiknas (2006). Permendiknas Nomor 22 tahun 2016 Tentang standart isi 
tentang Sekolah Menengah Atas.

Jakarta: Depdiknas

De lange, J. (2004). Mathematical, A Human

Endeavor $\left(2{ }^{r d}\right.$ Ed). San Fransisco:

W.H. Freeman and Company.

https://id.wikipedia.org/wiki/Olimpiade_Sain

s_Nasional di akses tanggal 12

Desember 2016

Kemendikbud, (2013). Kurikulum 2013.

Kompetensi dasar Sekolah Menengah

Pertama / Madrasah Tsanawiyah

(MTs). Jakarta.

NRC (1989). Every body Counts. A Report to

the nation on the Future of

Mathematic Education.Washington

DC: National Academy Press.

Shadiq, Fajar. (2014). Pembelajaran

Matematika. Yogyakarta: Graha

Ilmu 